\title{
The Environmental Safety Assessment of Cydiodine Powder
}

\author{
Guiming $\mathrm{Li}^{1,2}$, Jian $\mathrm{Fu}^{1,2}$, Shifa Yang ${ }^{1}$, Ning Liu ${ }^{2}$, Jing Shang ${ }^{2}$, Yue $\mathrm{Lu}^{2}$, Ying \\ $\mathrm{Li}^{2}$, Zengcheng Zhao ${ }^{1}$, Zhongli Huang ${ }^{1}$, Minyan Feng ${ }^{1}$, Shuqian Lin ${ }^{1 *}$, \\ Minxun Song ${ }^{{ }^{*}}$ \\ ${ }^{1}$ Institute of Poultry Science, Shandong Academy of Agricultural Science, Jinan 250023, China; \\ ${ }^{2}$ Shandong HaoTai Technology Pharmaceutical co., LTD, Jinan 250023, China.
}

Keywords: Cydiodine powder, Environment, Toxicology Security.

\begin{abstract}
The ecological security of Iodic agent was firstly studied in the domestic. To investigate environmental toxicology of the new developed of Cydiodine Powder(CDP), we research toxicity of CDP to zebrafish and earthworm, and the skin and eye irritation studies to rabbit. The static method, with reference to the chemical pesticide environmental safety evaluation test guidelines (GB/T 31270.12 2014), was used to research the toxicity to zebrafish. The toxicity to earthworm was studied with reference to the chemical pesticide environmental safety evaluation test guidelines (GB/T 31270.15 2014). The skin and eye irritation was tested reference to "disinfection technical specifications (2002 edition). The results appear to be $5.775 \mathrm{mg}$ of A.I. / L of $96 \mathrm{~h}$ LC50 value of CDP to zebrafish. The earthworm deaths is 0 with $100 \mathrm{mg}$ of A.I. / kg dry soil treatment after 14 day, and LC50 $>100 \mathrm{mg} / \mathrm{kg}$ dry soil. Skin irritation and eye irritation reaction maximum score was 0.33 and 2.75. This result Suggested that CDP was without excitant for skin and eye. The results of this study indicated that CDP is an environment friendly new disinfectant, and will not produce environmental toxicity.
\end{abstract}

\section{Introduction}

With increasingly complex breeding environment, strengthen the disinfection can reduce the spread of pathogenic microorganisms at the source. The future development of disinfectants is for the green environmental protection, broad spectrum efficiency, good safety, rapid, stable property, convenient for storage and transportation [1,2]. CDP, which was developed by Shandong Academy of Agricultural Science, has super molecular structure of disinfectant. Because the iodine preparation is not reported about environmental toxicology research, this study aimed at comprehensive and objective environmental safety of CDP, including the situation of disinfectant in the water, the soil and in direct contact with in the air.

\section{Materials and Methods}

\subsection{Experimental Animals}

Brachydanio rerio bought from Tai'an City Jinyuan aquarium, which was $2.16 \pm 0.212 \mathrm{~cm}$ long. Eisenia foetida was introduced from Tianjin Jialiming earthworm breeding Co. Ltd, which was length in $5 \sim 6 \mathrm{~cm}$, and weight between $0.400 \sim 0.550 \mathrm{~g}$. Seven health rabbit, weight $1.8 \sim 2.0 \mathrm{~kg}$, bought from Yangzhou university medical center.

\subsection{Reagents}

CDP was pilot producted by Shandong HaoTai technology pharmaceutical Co. Ltd, and the content specifications was 15\% (effective iodine). Reference material of fish toxicity test was 99.8\% potassium dichromate, and provided by Tianjin Kaitong chemical reagent Co. Ltd. The reference material of earthworm toxicity test was chlorine acetamide, and provided by Shanghai Aladdin reagent Co. Ltd. depilatory cream (100 g/tube) was provided by Guangzhou Aiqi cosmetics Co. Ltd. 


\subsection{Methods}

\subsubsection{Acute Toxicity Test to Fish}

Feeding conditions: the water aeration treatment more than $24 \mathrm{~h}$, water hardness between $10 \sim 250$ $\mathrm{mg} / \mathrm{L}$ (CaCO3), $\mathrm{pH}$ between $6.0 \sim 8.5$, dissolved oxygen (do) not less than $60 \%$ of the saturated air value, light/dark: $16 \mathrm{~h} / 8 \mathrm{~h}$, the temperature of $21 \sim 25 \mathrm{oC}$, a single test in the temperature control in \pm 2 oC. With reference to the chemical pesticide environmental safety evaluation test guidelines (GB/T 31270.12 2014) [3], the load was determined by half static method. Every group was 10 fish, and repeated 3 times. The poisoning symptoms and deaths of zebra fish was observed and recorded after 6 h, $24 \mathrm{~h}, 48 \mathrm{~h}, 72 \mathrm{~h}$ and $96 \mathrm{~h}$.

\subsubsection{Acute Toxicity Test to Earthworm}

Unified test conditions: temperature $20 \pm 2{ }^{\circ} \mathrm{C}$, humidity 70\% 90\%, and the light intensity 400 lx - 800 lx. Artificial soil in the study was in accordance with the chemical pesticide environmental safety evaluation test guidelines (GB/T 31270.15 2014) [4]. the soil was treated with the poison and evenly scattered into three beaker. Ten earthworms were taken into beaker, and sealed with plastic wrap and prick hole opener to keep the environment air permeability. At the same time we set up the control group. The poisoning symptoms and deaths of zebra fish was observed and recorded after $7 \mathrm{~d}$ and $14 \mathrm{~d}$.

\subsubsection{The Rabbit Skin Stimulus Test}

Before the test $24 \mathrm{~h}$, the rabbit hair of the spine was removed using depilatories, about $3 \mathrm{~cm} \mathrm{x} 3 \mathrm{~cm}$ in left, right sides of the spine. The next day, $0.5 \mathrm{~g}$ CDP direct evenly coated in the side of the area 2.5 $\mathrm{cm}$ x $2.5 \mathrm{~cm}$ unhairing complete skin, and covered with a layer of no stimulation plastic film, and then fixed with without stimulation rubberized fabric. The skin on the other side was blank control. After 4 $\mathrm{h}$, residual subjects was removed with warm water. skin reactions were observed After removal of subjects $24 \mathrm{~h}, 48 \mathrm{~h}, 72 \mathrm{~h}$, and scored for stimulus reaction with reference to "isinfection technical specifications (2002)".

\subsubsection{Rabbit Draize Test}

one side of the lower eyelid of health rabbit was dropped down gently, and $0.1 \mathrm{ml}$ the subjects drugs ( $0.25 \mathrm{~g} / \mathrm{L}$ cyclodextrin inclusion powdered iodine solution) was dropped into the conjunctival sac. And then, eyelids was immediately closed gently for about 1 min to prevent leakage in the store. The contralateral eye was treated with normal saline as normal controls. After 1 h, 24 h, 48 h, 72 h, days 4 and 7, we checked the eyes respectively.

\section{Results and Analysis}

\subsection{Acute Toxicity Test to Fish}

Experimental results was treated with the DPS V13.5 statistical software, the data was shown in Table 1. LC50 (24 h) of reference material potassium dichromate was $312.631 \mathrm{mg}$ a.i. / L, and conformed to the quality control requirements of chemical pesticide environmental safety evaluation test guidelines (GB/T 31270.12 2014) (200 $400 \mathrm{mg}$ a.i./L) [3]. The acute toxicity of CDP was middle toxicity, according to the grade of the acute toxicity of pesticides on fish.

Table 1 The acute toxicity results of CDP on zebrafish

\begin{tabular}{ccccc}
\hline Test Drug & Time(h) & LC50(mg a.i./L) & 95\% Confidence limit (mg a.i./L) & Correlati \\
\hline & 24 & 7.09 & $6.58-8.05$ & 0.81 \\
CDP & 48 & 6.56 & $6.21-7.06$ & 0.79 \\
& 72 & 5.99 & $5.71-6.33$ & 0.81 \\
Potassium dichromate & 96 & 5.78 & $5.52-6.07$ & 0.85 \\
\hline
\end{tabular}

\subsection{Acute Toxicity Test to Earthworm}

The data of experimental results was treated with the DPS V13.5 statistical software, the data was shown in Table 2. LC50 (14 d) of reference material chlorine acetamide was $33.247 \mathrm{mg}$ a.i. / L, and conformed to the quality control requirements of chemical pesticide environmental safety evaluation 
test guidelines (GB/T 31270.15-2014) [4]. The acute toxicity of CDP was low toxicity according to the grade of the acute toxicity of pesticides on earthworm. 
Table 2 The acute toxicity results of CDP on earthworm

\begin{tabular}{ccccc}
\hline Test drug & $\begin{array}{c}\text { (d) } \\
\text { Time }\end{array}$ & $\begin{array}{c}\text { LC50(mg a.i./kg Dry } \\
\text { soil) }\end{array}$ & $\begin{array}{c}\text { 95\% confidence limit } \\
\text { (mg a.i./kg Dry soil) }\end{array}$ & $\begin{array}{c}\text { Correlation } \\
\text { coefficient }\end{array}$ \\
\hline CDP & 7 & $>100$ & - & - \\
Chloroacetamide & 14 & $>100$ & - & - \\
\hline
\end{tabular}

\subsection{The Rabbit Skin Stimulus Test}

Rabbit skin was scored According to the score standard of skin irritation reaction, and the results are shown in table 3 . It can be seen that the skin irritation reaction score of subjects drug was a maximum average of 0.33 . According to the the intensity classification of the skin stimulation, CDP was without excitant.

Table 3 The resultof rabbit skin irritation reaction score

\begin{tabular}{cccccc}
\hline Outcome evaluation & Reaction score & NO.1 & NO.2 & NO.3 & Average score of skin irritation \\
\hline \multirow{2}{*}{$24 \mathrm{~h}$} & A & 0 & 0 & 0 & 0 \\
& B & 0 & 0 & 0 & 0 \\
$48 \mathrm{~h}$ & A & 0 & 0 & 0 & 0.33 \\
& B & 0 & 0 & 0 & \\
\hline \multirow{2}{*}{$72 \mathrm{~h}$} & A & 0 & 1 & 0 & 0 \\
& B & 0 & 0 & 0 & 0 \\
\hline
\end{tabular}

\subsection{Rabbit Draize Test}

Subjects drugs of rabbit skin irritation reaction score the results are shown in table 4 . It could be seen from the table that total score of the negative control group (each rabbit left eye) is zero. While total score of subjects drug group (each rabbit right eye) was 11, and the average score was 2.75. Referencing to the eye stimulate integral index (I.A.O.I), was without excitant to rabbit eyes.

Table 4 The result of rabbit eye irritation score

\begin{tabular}{|c|c|c|c|c|c|c|c|c|c|}
\hline \multirow{3}{*}{ Observation time } & \multirow{3}{*}{ Eye damage performance } & \multicolumn{8}{|c|}{ Score } \\
\hline & & \multicolumn{2}{|c|}{ NO.1 } & \multicolumn{2}{|c|}{ NO.2 } & \multicolumn{2}{|c|}{ NO.3 } & \multicolumn{2}{|c|}{ NO.4 } \\
\hline & & $\begin{array}{l}\text { Left } \\
\text { eye }\end{array}$ & $\begin{array}{l}\text { Right } \\
\text { eye }\end{array}$ & $\begin{array}{l}\text { Left } \\
\text { eye }\end{array}$ & $\begin{array}{l}\text { Right } \\
\text { eye }\end{array}$ & $\begin{array}{l}\text { Left } \\
\text { eye }\end{array}$ & $\begin{array}{l}\text { Right } \\
\text { eye }\end{array}$ & $\begin{array}{l}\text { Left } \\
\text { eye }\end{array}$ & $\begin{array}{l}\text { Right } \\
\text { eye }\end{array}$ \\
\hline \multirow{5}{*}{$\begin{array}{l}1 \mathrm{~h} \text { after } \\
\text { instillation of the } \\
\text { test drug }\end{array}$} & Iris & 0 & 0 & 0 & 0 & 0 & 0 & 0 & 0 \\
\hline & Cornea & 0 & 0 & 0 & 0 & 0 & 0 & 0 & 0 \\
\hline & excreta & 0 & 0 & 0 & 0 & 0 & 0 & 0 & 0 \\
\hline & Conjunctival hyperemia & 0 & 0 & 0 & 0 & 0 & 0 & 0 & 0 \\
\hline & Conjunctival edema & 1 & 0 & 1 & 0 & 0 & 1 & 1 & 0 \\
\hline \multirow{5}{*}{$\begin{array}{l}24 \mathrm{~h} \text { after } \\
\text { instillation of the } \\
\text { test drug }\end{array}$} & Iris & 0 & 0 & 0 & 0 & 0 & 0 & 0 & 0 \\
\hline & Cornea & 0 & 0 & 0 & 0 & 0 & 0 & 0 & 0 \\
\hline & excreta & 0 & 0 & 0 & 0 & 0 & 0 & 0 & 0 \\
\hline & Conjunctival hyperemia & 1 & 0 & 0 & 1 & 0 & 0 & 0 & 0 \\
\hline & Conjunctival edema & 1 & 1 & 1 & 0 & 0 & 1 & 1 & 0 \\
\hline \multirow{5}{*}{$\begin{array}{l}48 \mathrm{~h} \text { after } \\
\text { instillation of the } \\
\text { test drug }\end{array}$} & Iris & 0 & 0 & 0 & 0 & 0 & 0 & 0 & 0 \\
\hline & Cornea & 0 & 0 & 0 & 0 & 0 & 0 & 0 & 0 \\
\hline & excreta & 0 & 0 & 0 & 0 & 0 & 0 & 0 & 0 \\
\hline & Conjunctival hyperemia & 0 & 0 & 0 & 0 & 0 & 0 & 0 & 0 \\
\hline & Conjunctival edema & 0 & 0 & 0 & 0 & 0 & 0 & 0 & 0 \\
\hline \multirow{5}{*}{$\begin{array}{l}72 \mathrm{~h} \text { after } \\
\text { instillation of the } \\
\text { test drug }\end{array}$} & Iris & 0 & 0 & 0 & 0 & 0 & 0 & 0 & 0 \\
\hline & Cornea & 0 & 0 & 0 & 0 & 0 & 0 & 0 & 0 \\
\hline & excreta & 0 & 0 & 0 & 0 & 0 & 0 & 0 & 0 \\
\hline & Conjunctival hyperemia & 0 & 0 & 0 & 0 & 0 & 0 & 0 & 0 \\
\hline & Conjunctival edema & 0 & 0 & 0 & 0 & 0 & 0 & 0 & 0 \\
\hline \multicolumn{2}{|c|}{ Total score } & 3 & 1 & 2 & 1 & 0 & 2 & 2 & 0 \\
\hline
\end{tabular}




\section{Discussion}

CDP was composed of iodine, $\beta$ cyclodextrin, potassium iodide, twain and other raw materials. The result of iodine volts toxicology by Liu shown that the LD50 in mice was greater than 5000 $\mathrm{mg} / \mathrm{kg} \cdot \mathrm{BW}$, and it was actually non-toxic [1]. Accumulation coefficients were greater than 5 for weak cumulative effect. Guifang Xu (1986) reported that rat, $1000-2000 \mathrm{mg} / \mathrm{kg}$ dose, taking 34 days in a row, the growth and development of the oral cyclodextrin group (1000-2000 mg/kg dose, last 34 days) and control group rats was without any differences [5]. Fang Xu (1991) concluded that oral and intravenous LD50 of twain-80 was $25 \mathrm{~g} / \mathrm{kg}$ and $5.8 \mathrm{~g} / \mathrm{kg}$, and the hemolytic effect of twain -80 was the slightest one in Twain's class. Feeding experiment of different concentrations of potassium iodide (KI) proved that until $30 \mathrm{mg} \cdot \mathrm{kg}-1 \cdot \mathrm{d}-1 \mathrm{KI}$ would have toxicity to animals. CDP was $\beta$ cyclodextrin inclusion compound with iodine, and the clathrate was a physical combination between the two substances and no change in chemical properties. So, the toxicology of inclusion would not change compared with the original material. But the environmental toxicology CDP was comprehensive analysised and evaluated considering the safe use of CDP.

This study found that the LC50 value (96 h) of CDP was $5.775 \mathrm{mg}$ a.i. / L on zebrafish, and namely effective iodine concentration was $5.775 \mathrm{mg} / \mathrm{L}$. The test conducted by Yandong Zhang, etc. in 1998 confirmed that $24 \mathrm{~h}, 48 \mathrm{~h}$ hepatopancreatic half lethal concentration and safe concentration of povidone iodine is respectively 499, 355 and $53.6 \mathrm{mg} / \mathrm{L}$ to Macrobrachium rosenbergii postlarva, also it explained the lethal concentrations of iodine prawns and safe concentration is higher. What's more, acute toxicity test on earthworm certified that CDP complied with environmental requirements. The ground and metope disinfection tests also prove that the iodine residues had no significant effect on the environment after scouring. In a word, CDP would not produce environmental toxicity.

It was reported that effective concentration 5\% iodine volts was nonirritant for complete skin and damaged skin, and have slight irritation on vaginal mucosa. The rabbit skin stimulus test indicated that povidone iodine solution had no irritating effection and allergic reaction on guinea pig and rabbit skin. In addition, Xidi iodine compound were had no obvious stimulation and systemic adverse reactions to oral cheek pouch mucosa of healthy rats, which were fed Xidi iodine compound. Likewise, This research results showed that CDP had no irritation to skin and eyes. In conclusion, CDP was nonirritant disinfectant to animal. Moreover, CDP is environmentally friendly new disinfectant, and will not produce environmental toxicity.

\section{Acknowledgments}

This study was funded by Special Fund for Agro-scientific Research in the Public Interest (201303040-10), Jinan star program (201406024), Science Foundation of Shandong Academy of Agricultural Sciences (2015YQN58) and Shandong province modern agriculture industry technology system (SDAIT-13-011-01).

\section{References}

[1] Meizhan Tian, Zhimin An, Ming Ji, et al. Application of veterinarians and veterinary disinfectant disinfection in aquaculture. Technology Information of Animal Husbandry and Veterinary Science. 2013, 12: 9.

[2] Disinfection Technical Specifications (2002 edition), Health Ministry of China. 2012, 4.

[3] Chemical pesticide environmental safety evaluation test standards (GB/T 31270.12), General Administration of Quality Supervision, Inspection and Quarantine of the People's Republic of China. 2014.

[4] Chemical pesticide environmental safety evaluation test standards (GB/T 31270.15), General Administration of Quality Supervision, Inspection and Quarantine of the People's Republic of China. 2014.

[5] Guifang Xu, Tingsen Shi. Food additives $\beta$-cyclodextrin toxicity. Journal of Food Science. 1986, 08: 23-28. 